THEORIA ET HISTORIA SCIENTIARUM, VOL. VIII, $\mathrm{N}^{\circ} 2$

Ed. Nicolaus Copernicus University 2008

Maria Magoula Adamos

\title{
What is the Role of Imagination in Emotion?
}

\begin{abstract}
Over the last forty years most scholars have viewed emotion as some type of evaluative propositional attitude, usually identified as belief or judgment, which is often accompanied by physiological sensations and feelings. Historically, the role of imagination in emotions has been ignored, or when it has been mentioned, has not been sufficiently explored. In this essay I challenge the prevalent cognitivist view, and I argue that often times imagination through its medium of mental pictures can better explain our emotional experiences. In particular, I examine a case of irrational fear and a case of humiliation where the requisite evaluative beliefs are missing, and I show that even though mental pictures are non- propositional, as they don't require concepts for their realization, they are in a better position to explain emotions that lack an evaluative propositional attitude such as belief or judgment. Given that mental pictures, like propositional attitudes, are intrinsically intentional and representational, they are also able to account for the intentionality of the emotion, and, as a result, they can identify it as the kind of emotion it is.
\end{abstract}

\section{Introduction}

Over the last forty years most scholars have viewed emotions as some type of evaluative propositional attitudes, usually identified as beliefs or judgments, which are often accompanied by physiological sensations and feelings. Historically, imagination's important role in emotions has been neglected, and when it has been mentioned, it has not been sufficiently explored. ${ }^{1}$ However, a more thorough

${ }^{1}$ Some notable exceptions are Michael Stocker, Patricia Greenspan and Martha Nussbaum. See Stocker 1987, Greenspan 1988, and Nussbaum 2001. 
examination reveals that imagination, through its medium of mental pictures, is better equipped than either beliefs or judgments to explain an emotion. Because mental pictures do not employ propositions or concepts for their realization, they are in a better position to explain emotions that lack an evaluative propositional attitude (i.e. a belief or judgment.) Given that mental pictures, like propositional attitudes, are intrinsically intentional and represen-tational, they are also able to account for the intentionality of the emotion, and, as a result, they can identify it as the kind of emotion it is.

\section{Cognitivism}

Although cognitivism has lost some ground recently in the philosophical circles, it is still the favorite view of many scholars of emotions. According to cognitivism, emotions are not simply feelings or perceptions of physiological sensations. On the contrary, emotions along with other mental states such as beliefs, mental pictures, desires, intentions etc. have a common characteristic: they are directed toward something or someone; they have, in other words, intentional objects. ${ }^{2}$ The intentional object enables us to identify an emotion and distinguish it from other emotions and mental states. If I characterize the object of my emotion as dangerous, then I will be able to identify it as fear, or, if I think that the object of my emotion has suffered a great loss, I will be able to identify it as pity, and so on. ${ }^{3}$

According to the cognitivist view, emotions are essentially propositional cognitive attitudes such as evaluative beliefs, thoughts or judgments, although it is granted that they are often accompanied by feelings, physiological disturbances, etc. ${ }^{4}$ Consequently, making cognition a necessary, and, sometimes sufficient condition of the emotion, cognitivists are able to account for the intentionality of the emotion. Cognitive states such as beliefs and judgments to essentially

2 The intentionality of mental states was first captured by Franz Brentano, and then was brought to the Analytic Tradition by Anthony Kenny. See Brentano (1973) and Kenny (1963).

${ }^{3}$ One might argue that with the scientific advances in psychology, neurology and physiology, we might be able to distinguish the emotions simply by referring to their physiological patterns. This might be true. Yet, we should not be too ready to surmise that the program will eventually succeed. For whatever the eventual success of the program may be, it surely cannot elucidate the common sense understanding we already have of the emotions. Indeed, the success or failure of any such program is in the end going to be measured by how well it correlates with our common sense understanding of the emotions. Since our common sense understanding of the emotions is pretty good and working for us, an adequate theory of emotions should try to elucidate upon this understanding rather than ignoring it.

${ }^{4}$ As we will see in the following pages, most cognitivists disagree about the role of feelings in the emotion. 
intentional. What is more, through the evaluative cognitions cognitivists are able to identify the emotion as the kind of emotion it is, as well as distinguish it from other emotions and mental states. For instance, what distinguishes envy from jealousy is that in the case of envy I believe or think that you have something that I want to have, whereas in the case of jealousy I believe that something or someone that should rightfully be favored and enjoyed by me is being favored and enjoyed by someone else.

Contemporary philosophical cognitivism primarily began with Anthony Kenny's, Action, Emotion and Will. In this influential work Kenny argues that emotions must involve an evaluative belief and that feelings are inessential to the definition of emotion: "Bodily changes might be a vehicle of an emotion, but they are not themselves an emotion" (Kenny, p. 88). According to Kenny, each type of emotion has its own formal object: "Emotional attitudes, like other mental attitudes, have formal objects...In fact, each of the emotions is appropriate - logically and not just morally appropriate - only to certain restricted objects. One cannot be afraid of just anything, nor happy about anything whatsoever. (Kenny, p. 192). In fact, Kenny thinks that it is not just the object itself that specifies the emotion, but what the subject believes about the object in question:

It is not, of course, correct to say e.g. that the formal object of envy is another's good tout court: one must say that it is something believed to be good and believed to belong to another...The description of a mental attitude such as an emotion, unlike a description of the formal object of a non-intensional action, must contain reference to belief. Only what is wet in fact can be dried; but something which is merely believed to be an insult may provoke anger (his italics). (Kenny, pp. 193-4).

It is clear here that Kenny advocates a cognitivist view, as he thinks that a belief is necessary for the definition and identification of emotion.

Another proponent of cognitivism, Gabriele Taylor, also tells us that beliefs are constitutive of emotions:

Over a wide range of emotions...beliefs are constitutive of the emotional experience in question. They are constitutive in two ways. Firstly, one (or more) of the beliefs makes the emotional experience what it is, it identifies it as, for example, anger, and so differentiates it from other states, such as jealousy or envy. But secondly, there will also be further beliefs because of which the person experiencing the emotion will hold the identificatory belief(s)... Normally, if I feel fear, for example, then I believe the situation confronting me to be dangerous or harmful, and I believe this because I believe that it has some particular characteristic in virtue of which it is harmful (Taylor, p. 2). ${ }^{5}$

\footnotetext{
${ }^{5}$ Taylor, G., Pride, Shame and Guilt, Clarendon, 1985.
} 
In the above quote Taylor advocates a cognitivist account where a cognitive state such as belief becomes an essential component of the emotion. Although both Taylor and Kenny think that bodily feelings are an important and perhaps necessary element of the emotion, they also agree that feelings do not play an essential role in the definition and identification of emotion.

A slightly different view is expressed by Alston, Lyons, De Sousa, Gordon and Greenspan, who argue that both evaluative propositional attitudes and feelings are essential elements of emotions. Although these theorists disagree as to the precise role and nature of feelings as well as to the type of cognition involved, they all agree that emotions must involve some type of evaluative propositional attitude. For instance, Lyons argues that the evaluative belief causes the physiological sensations of emotion (Lyons, 1980, p. 57). Likewise, Greenspan proposes that emotional feelings are intentional affective states that are about or directed towards a corresponding evaluative proposition, which may be held in mind without assent (Greenspan, 1988, p.7).

A more radical view, however, is expressed by Robert Solomon and Martha Nussbaum, In the section 'Emotions and Judgments' of his book The Passions, Solomon argues that an emotion is a judgment (or a set of judgments):

An emotion is a basic judgment about our Selves and our place in our world.... My anger is that set of judgments. Similarly, my embarrassment is my judgment to the effect that I am in an exceedingly awkward situation. My shame is my judgment to the effect that I am responsible for an untoward situation or incident. My sadness, my sorrow, and my grief are judgments of various severity to the effect that I have suffered a loss. An emotion is an evaluative (or a 'normative') judgment, a judgment about my situation and about myself and/or about all other people (p. 126). ${ }^{6}$

Here, although Solomon is in agreement with most cognitivists that an emotion requires specific evaluative states such as beliefs or judgments, he, unlike them, believes that a judgment (or a set of judgments) is also sufficient for an emotion. ${ }^{7}$

${ }^{6}$ I have argued elsewhere that Solomon's account faces difficulties. One of the greatest problems in Solomon's theory is that it fails to distinguish between emotional judgments and «cold-blooded», nonemotionally relevant judgments, and, as a result, it fails to show how we would be able to recognize that a certain judgment we make is an emotionally relevant judgment as opposed to a regular judgment.

${ }^{7}$ In his talk in the Philosophy and the Emotions Conference given by the Royal Institute of Philosophy at the University of Manchester (2001), Solomon put forth the view that emotions are «affective» judgments. However, it seems that replacing «judgments» with «affective judgments ${ }^{\circledR}$, doesn't do the trick, since Solomon still has to provide the criteria for distinguishing affective or emotional judgments from regular, «cold-blooded» judgments. 
Also, Martha Nussbaum in her book Upheavals of Thought: The Intelligence of Emotions advocates a cognitivist view:

At this point we are in a position to conclude not only that judgments of the sort we have described are necessary constituent elements in the emotion, but also that they are sufficient. For we have argued that if the emotion is not there we are entitled to say that the judgments themselves are not fully or really there (p. 43-44). ${ }^{8}$

Nussbaum's account is very similar to Solomon's, for they both believe that evaluative judgments are sufficient for emotions. ${ }^{9}$

Even though I agree with cognitivism's insight that emotions typically involve some type of evaluative intentional state, I shall argue that in some cases, less epistemically committed, non-propositional evaluative states, such as mental pictures can do a better job in identifying the emotion, or, in providing its intentional object. In order to show this, I shall examine a case of irrational fear and a case of humiliation where the requisite identificatory beliefs are missing. ${ }^{10}$

\section{The Fear of the Harmless Spider}

According to most cognitivists, to experience fear is to hold the evaluative belief, thought or judgment that the object of fear is dangerous. Such belief is supposed to provide the intentionality of fear, identify it as the kind of emotion it is, and thereby differentiate it from all other emotions and mental states. However, although this may be true in some cases of fear, oftentimes one might be afraid without believing, thinking or judging that one is in danger. This is usually the case with irrational fears, where one's beliefs are at odds with one's emotion. For instance, we can imagine a situation where a perfectly rational person is afraid of a harmless spider, even though she is certain that it is not

${ }^{8}$ Nussbaum later in her book acknowledges that imagination also plays an important role in the emotion, but she does not believe that imagination could count as a necessary condition for the emotion. See Nussbaum 2001, p. 64-67. Also, in the chapter «Humans and Animals» Nussbaum allows for a nonlinguistic symbolism in the emotions of animals, human infants, young children, and sometimes in humans. See p. 127.

${ }^{9}$ As Nussbaum notes, despite the similarities, there are differences between her account and Solomon's. While Solomon sees emotions as «the source of our values», Nussbaum tries to present «the valuational nature of our appraisals from the internal viewpoint of the person having the emotional experiences.

${ }^{10}$ Although my argument will eventually show that all cognitivist accounts that claim that emotions require evaluative propositions are deficient, for the sake of clarity and simplicity, I will suppose in my examples the most prominent cognitivist view, according to which the intentional propositional states necessary for the emotion are identified with beliefs and judgments. 
dangerous. But if this is the case, then cognitivism faces serious difficulties. For since the identificatory belief is missing, it is unable to account for the intentionality of fear, and, as a result, it fails to identify the emotion. How is cognitivism to solve the problem?

A cognitivist could appeal to unconscious beliefs. She could say that the person experiencing the irrational fear of the spider might think (consciously) that she holds the belief that the spider is harmless. Yet, the real belief, so to speak, constitutive of her fear is that the spider is dangerous. The person is simply not aware of such belief. Suppose that it is true that the arachnophobic does in fact have the unconscious belief that the spider is dangerous. But then one wonders, how can this belief, which is not consciously entertained by the person, be constitutive of her emotion or identify her fear? If beliefs are constitutive of emotions, and if they are needed in order to identify the emotions, then it is difficult to see how it is possible for one to experience an emotion without being aware that they hold the relevant belief. ${ }^{11}$ How can I be afraid of the spider, when I am not aware that I hold the belief that it is harmful, especially if fear entails the belief that one is in danger or that the object of fear is harmful?

The problem lies in the cognitivists' contention that beliefs are constitutive of emotion. For this to be the case, when one is conscious of one's emotion, one also has to be conscious of one's beliefs that constitute the emotion. Let me spell out the argument a bit more clearly:

a) The belief that the spider is dangerous is consciously inaccessible.

b) The fear of the spider is consciously accessible.

c) Beliefs are constitutive of fear.

d) Anything constitutive of fear should be consciously accessible.

Therefore,

e) The unconscious belief cannot be constitutive of fear.

Now, it may be true that the arachnophobic has an unconscious belief. However, if the unconscious belief is to play any role in the emotion, it can only be the cause of the emotion rather than an essential element of it. But this is something that the cognitivist would not accept, since a belief according to her is not simply the cause of the emotion, but an essential part of it. So, it seems that appealing to unconscious beliefs will not help the cognitivist much.

Maybe there is another route available to the cognitivist. She might try to explain the emotion through an associationist approach: Although our arachnophobic does not believe that the present spider is dangerous, she does

\footnotetext{
${ }^{11}$ It is important to note here that I am not implying that there are no unconscious beliefs in emotions. Rather, I am arguing that the cognitivist view cannot really appeal to unconscious beliefs in order to solve the problem of emotions that lack an identificatory belief.
} 
hold other beliefs in the 'region', as it were, of the dangerousness of the present spider. That is, she might believe the following:

'Spiders are disgusting and ugly creatures'.

'Being bitten by a spider is unpleasant'.

'Some spiders are genuinely dangerous'.

'The present spider looks like a truly dangerous spider, e.g. a "black widow".

"Black widows" are dangerous spiders'.

'Being bitten by this particular spider would be as unpleasant and/or harmful as being bitten by a genuinely dangerous spider, i.e. a "black widow".

Here, the cognitivist could apply Hume's theory ${ }^{12}$ of association of ideas: there are enough similarities between this particular spider and something genuinely dangerous, i.e. "black widows", and because of the similarities, one's fear of "black widows" is being transferred to the harmless spider, although one does not believe that the spider is dangerous. ${ }^{13}$ In this case, the belief that identifies the fear is the conjunction:

"There are many similarities between the present spider and "black widows" and “black widows” are dangerous spiders'.

This approach seems to do a better job in explaining the problem of irrational fear while being in accordance with cognitivism. Perhaps it is not really necessary to have the belief that the object of fear is dangerous in all cases of fear. Other beliefs in the region of dangerousness of the object of fear can equally qualify as being constitutive of the emotion. However, there are problems with this view too.

Let us say, for the sake of the argument, that our arachnophobic does in fact associate the dangerousness of other dangerous similar creatures with the harmless spider. In order to make her case, however, the cognitivist needs a belief that would be entailed by the agent's fear, such as 'this (particular) spider is dangerous'. Only then would the cognitivist be able to identify the agent's current emotion as fear. And, as we have seen, our arachnophobic does not have such belief. Remember, the cognitivist does not think that cognitions such as beliefs are simply present in emotions. She thinks that they constitute the emotions or that they are logically necessary for the emotions. Holding beliefs in 'the region

12 See David Hume (1962).

${ }^{13}$ We have to notice that in order for this argument to work, it will not be enough for one to associate the negative qualities of other dangerous things with the negative qualities of the particular spider. For it is possible for one to believe that a certain object has many negative qualities and yet not believe that the object itself is dangerous. In this case, one has to believe that the other objects whose negative qualities are similar to those of the present object are themselves dangerous and thereby transfer one's fear from these other dangerous objects to the present object. 
of dangerousness' will not do, because the cognitivist has to admit that in some cases of fear the belief 'the object of the current fear resembles something dangerous' should also be constitutive of fear. Yet, a cognitivist would not want to say that. Resembling something dangerous is not a logical entailment of fear. For, according to the cognitivist, it is the dangerousness of the present object that is entailed by the present fear, not its similarities with something that is taken to be truly dangerous, especially when the similarity is not taken to extend to the dangerousness of the present object of fear. The belief that a thing resembles something genuinely dangerous does not imply the belief that it is dangerous. Resembling $\mathrm{X}$ does not imply X. For instance, I see someone resembling Charles Manson, and I believe that Charles Manson is very dangerous. Obviously, such resemblance does not entail that this particular person is dangerous. Therefore, the cognitivist cannot say that the belief that the present spider resembles a "black widow", which the agent believes is genuinely dangerous, implies the belief that $z^{\prime} z$ is actually dangerous. For, unless the similarities between the "black widows" and the present spider extend to the dangerousness of the present spider, the cognitivist cannot explain, nor identify the arachnophobic's fear. So, the attempt to explain the irrational fear through the associationist approach, like the attempt of appealing to unconscious beliefs, has failed.

Yet, perhaps there is still a way out for the cognitivist. It might be that the arachnophobic has the evaluative belief that the spider is fearful, for it is difficult for someone to say that she is afraid of something, if she does not find that thing at least fearful. However, if the only evaluative belief the cognitivist can produce in her analysis of the irrational fear is that the object of fear is fearful, she is making a big retreat. It is a retreat because the cognitivist cannot avail herself of an emotional vocabulary, and hence she is begging the question. For, in order to specify the belief which is supposed to identify and explain the emotion, the cognitivist uses the vocabulary that describes the same emotion she is supposed to explain. What we need to know in order to explain fear is not that the agent finds the object fearful, but why she finds it fearful. And, if this is the case, then the cognitivist is still in no position to identify the arachnophobic's emotion. ${ }^{14}$

The above examples have shown that there is no evaluative belief, which is essential to irrational fear. Hence, evaluative beliefs are not as omnipresent in emotions as most cognitivists think, and cognitivism is unable to account for the intentionality of irrational emotions. Consequently, cognitivism cannot identify nor distinguish such emotions. How we are to understand the intentionality of

${ }^{14}$ Also, Paul Griffiths argues in What Emotions Really Are (although for different purposes) that emotionally relevant properties such as lovableness, hatefulness and infuriatingness are responsedependent properties because they are defined in terms of the emotion they elicit. See his discussion on p. 41. 
irrational emotions will emerge towards the end of the last section. Now let us turn to a case of humiliation that would also show that cognitivism is insufficient in explaining the emotions.

\section{A Case of Humiliation}

Let us assume, for the sake of argument, that there is an essential belief or propositional thought involved in humiliation, namely, the belief that my situation is degrading or my status has been degraded (either in my own eyes or in the eyes of others). It can still be shown that there are cases of humiliation in which such belief is absent. Consider such a case as it is presented in James Joyce's short story 'The Dead'. ${ }^{15}$ The protagonist, Gabriel, after spending his evening at a party given by his aunts, is now with Gretta, his wife, who is telling him about a certain boy in the gasworks who died for her sake. Gabriel, in an effort to stop her, is making ironic comments, but Gretta does not even notice his irony:

Gabriel felt humiliated by the failure of his irony and by the evocation of this figure from the dead, a boy in the gasworks. While he had been full of memories of their secret life together, full of tenderness and joy and desire, she had been comparing him in her mind with another. A shameful consciousness of his own person assailed him. He saw himself as a ludicrous figure, acting as a penny-boy for his aunts, a nervous, wellmeaning sentimentalist, orating to vulgarians and idealizing on his own clownish lusts, the pitiable fatuous fellow he had caught a glimpse of in the mirror (p. 216). ${ }^{16}$

What is the identificatory belief in Gabriel's humiliation? One may be tempted to say that the identificatory belief is that his status has been degraded. But Joyce nowhere tells us that Gabriel holds such belief or thought. Alternatively, one might think that the requisite belief is that he is a ludicrous figure, or that he is acting as a penny-boy for his aunts, etc. But, these beliefs, if indeed Gabriel does hold them, are not entailed by Gabriel's humiliation. One could feel humiliated without having such beliefs. Yet, an objector could plausibly claim that in so many words, the aforementioned beliefs, (i.e. that he is a ludicrous figure, that he is acting as a penny boy for his aunts, etc.) if they were Gabriel's beliefs, could add up to the belief that Gabriel is degraded and thereby they could constitute his humiliation. That may be true. I do not deny that there could be cases of humiliation where a person's beliefs that he is a ludicrous figure,

15 Although the same story is used in G. Taylor's Pride, Shame and Guilt, my discussion here is concentrated on an entirely different aspect of the story.

16 Joyce, J., Dubliners, New York: The Viking Press, 1961. 
idealizing on his own clownish lusts, etc., could add up to the belief that one is degraded. But this is not how Joyce depicts Gabriel. What Joyce writes is: 'He saw himself as a ludicrous figure, .... nervous, well-meaning sentimentalist, orating to the vulgarians...the pitiable fatuous fellow he had caught a glimpse of in the mirror' [my italics]. It is important to notice that Joyce does not tell us that Gabriel believes that he is a fatuous fellow, acting as a penny boy for his aunts, etc. If so, then it is possible for Gabriel to believe that he is a wonderful person that everyone likes and admires, but picture, or see himself as a ludicrous figure and fatuous fellow who acts as a penny boy for his aunts, etc. That is, it is perfectly compatible with Joyce's description that, all things considered, Gabriel's stable belief is that he is a kind person helping his aunts, valiantly trying to enlighten the people he is lecturing to, and that, so far from being ludicrous, he is in his own way improving the lot of the people around him. But if this is the case, then although Gabriel does feel humiliated, he does not believe that he is degraded (either in his own eyes, or the eyes of others.) Accordingly, feeling humiliated does not require the belief that one is degraded. If George W. Bush slips and falls down while jogging, he could well feel humiliated without at all believing that he is degraded.

But if Gabriel, as described by Joyce, does not believe that he is degraded, how is he able to identify his emotion as humiliation? The clue lies in Joyce's use of 'He saw himself as a ludicrous figure, acting as a penny boy for his aunts', etc. To follow up this clue, I will borrow some ideas from Francis W. Dauer's essay 'Between Belief and Fantasy: A Study of the Imagination' and suggest that what brings about Gabriel's humiliation is his picturing or seeing himself in a certain way. ${ }^{17}$ Such 'picturing' or 'seeing' is closer to imagination than to belief.

\section{Imagination vs. Belief}

According to Dauer, there are instances of imagination, which use pictures instead of concepts as their medium. For example, there is a use of seeing or picturing as where the proposition $\mathrm{T}$ see or picture $\mathrm{X}$ as being $\mathrm{Y}^{\prime}$ can be true, while the viewer knows $\mathrm{X}$ is not $\mathrm{Y}$ (Dauer, p. 266). This seems to be the case with a lot of attitudes towards ourselves and others. We do say things such as 'she still sees him as the young man she met at the prom, while she knows that he is her middle-aged husband'. Or, we say 'he still sees himself as the best player, when he knows otherwise'. Does this mean that the wife and the player have two contradictory beliefs? Of course not. Generally, we do not accuse people who say such things of

${ }^{17}$ Dauer, R, 'Between Belief and Fantasy: A Study of the Imagination' in Pursuit of Reason: Essays in Honor of Stanley Cavell, ed. Cohen, Guyer, and Putnam, Lubbock: Texas Tech Press, 1993. 
himself to be the best player, while he knows that he is not, he is expected not to get annoyed or angry when he doesn't get the Best Player of the Year Award, or when others do not include his name among the best players. However, such person is still expected to show some signs that he sees himself as the best player. For instance, he might feel pride and joy when little boys come and tell him that they believe he is the best player, or he might give advice to young players with the air of a person who is the best player, etc. The medium for this state of imagination is mental pictures instead of propositions. Pictures have different logical features from propositions. Three of the distinct logical features of pictures are the following:

1) They are representational.

2) There are objects and people depicted in the picture.

3) Some pictures can portray actual objects and people, and the portrayed objects and people may or may not portray the actual persons aptly (Dauer, p. 271). According to this reading, to see or picture $X$ as being $Y$ is to see the picture

which depicts $\mathrm{Y}$ as an apt portrait of $\mathrm{X}$. Pictures are the right medium for this kind of imagination, because while a proposition is simply true or false of a person (a concept either subsumes or doesn't subsume a person) a picture can portray a person with varying degrees of aptness. 'Being a young man' is simply false of the middle-aged husband, but a picture of a young man can still portray the husband aptly; perhaps it is because of the lively behavior. The judgment by which we judge $\mathrm{Y}$ to be an apt portrait of $\mathrm{X}$, is essentially an aesthetic judgment; accordingly, if one sees $\mathrm{Y}$ as an apt portrait of $\mathrm{X}$ and another does not, this does not mean that one is right and the other wrong. Hence, pictures cannot be reduced to propositions and beliefs because they lack the truth or falsity dimension that is ontologically connected to propositions and beliefs. Further, whether a picture is an apt portrait of someone or something is a purely aesthetic matter. One either sees or does not see a certain portrait as apt. There are no objective criteria by which one can judge or persuade another that a certain picture is an apt portrait of someone or something. Aptness is something one sees for oneself. One cannot take someone else's word for it, as one might in order to believe a proposition. And even if there is a good and bad taste in aesthetic judgments, one cannot be said to have made a mistake if one takes a picture to portray something or someone aptly. Yet, one can be said to be mistaken if one forms a false belief about something or someone.

\section{Humiliation and Imagination}

Now let us return to Gabriel's case and see how this type of imagination explains his humiliation. It is true that Gabriel has many beliefs regarding that 
evening. However, we need not ascribe to him the beliefs that he is a ludicrous, pitiable, fatuous fellow, idealizing on his own clownish lusts, etc. He certainly has, for instance, the beliefs that he is helping his aunts for the party he thought uninteresting, that he was talking to an uncultured audience, that his wife, a woman that he very much loves, was not listening to him when he was talking to her about their secret life together, etc. These beliefs function as external constrains in order for Gabriel to see or picture himself as a ludicrous figure, fatuous fellow, orating to the vulgarians, etc. Taking such pictures to be apt portraits of himself brings about Gabriel's humiliation.

To illustrate the point, let us modify a bit Gabriel's case. Suppose that Gabriel knows that the propositions T am a ludicrous, fatuous fellow', etc. are false. Yet, he takes them to apply to him at that moment. But if the propositions are false, how could they apply to him? Obviously, they must apply to him in some way other than truth. The only alternative, it seems, is that Gabriel sees the picture of a ludicrous figure, fatuous fellow, etc., as an apt portrait of himself at that moment. And, given that aptness lacks the truth or falsity dimension, it is perfectly understandable that while Gabriel thinks that the propositions "I am a ludicrous, fatuous fellow" are false, as he does not think that they truly apply to him, he sees the mental picture of a ludicrous, fatuous fellow as an apt portrait of him.

Now, the question is how picturing oneself as a ludicrous figure, or fatuous fellow, etc. amounts to humiliation. Well, it seems that by picturing himself as a fatuous fellow and the like, Gabriel also pictures himself as having been degraded, because he finds the portrayed person in the picture to have been degraded. This, in turn, brings about Gabriel's humiliation. Therefore, although Gabriel does not have the relevant identificatory belief that his situation is degrading, by picturing himself in a 'degrading light' he is able to identify his emotion as humiliation.

But one might ask, why can we not say that Gabriel just exhibits a case of free imagination, and so, he is imagining the proposition $\mathrm{T}$ am a ludicrous, pitiable fellow' to be true? For, if he does imagine such a proposition as being true, then we can explain his humiliation by saying that he also imagines that being a fatuous, ludicrous figure is degrading, and consequently feels humiliation. This might be feasible in some cases. ${ }^{18}$ However, this is not what happens in Gabriel's case. According to Joyce, Gabriel is not daydreaming, nor is he fantasizing. The events of that evening led him to picture himself as a ludicrous fellow, etc. Had

${ }^{18}$ Greenspan (1988) and Stocker (1987) have also suggested that emotions can arise simply by imagining certain propositions to be true. Although I agree with their insights, I also think that the main medium of imagination is mental pictures, and not propositions or concepts, for, while concepts and propositions could be true or false, pictures could merely be apt or inapt. 
those events not happened, he would not have pictured himself in that way. That is, there are external conditions and constraints that led Gabriel to picture himself as a ludicrous and fatuous fellow.

Yet, again, one might object, if I allow beliefs to play the role of external constraints, do I not also agree with the cognitivist, who believes that cognitive states such as beliefs are necessary for the emotion? To say that beliefs are necessary for emotions is a triviality. Surely emotions require beliefs. However, what is problematic with cognitivism is not the claim that beliefs or judgments are necessary for emotions, but that in each emotion there is a particular evaluative belief, which is essential to the emotion and identifies it as the kind of emotion it is. Also, we have to remember that although Gabriel's beliefs function as conditions and external constraints for his humiliation, these conditions are not decisive; for, one can meet the conditions, have all those beliefs, and still not picture oneself in such a way, and, therefore, not feel humiliated. That is, the beliefs that lead Gabriel to his picturing, and consequently to his humiliation, are just vehicles for his emotion, and as such, they do not play any essential role in his humiliation.

\section{Irrational Fear: A Possible Solution}

We are now equipped to explain the case of the irrational fear of the spider. As we recall, our arachnophobic lacks the evaluative belief 'this spider is dangerous' that would identify and explain her fear. I would like to suggest that in such a case, although the person believes that the spider is harmless, she pictures or sees it as something genuinely dangerous, a black widow perhaps, and seeing this picture as an apt portrait of the present harmless spider, brings about her fear. Furthermore, the arachnophobic's beliefs that are in the 'region' of dangerousness, i.e. 'spiders are ugly and disgusting creatures', 'to be bitten by them is unpleasant', 'this spider resembles a "black widow" and "'black widows" are dangerous spiders', function as external constraints and conditions for picturing or seeing the present spider as a dangerous "black widow." If the arachnophobic had none of these (or relevant) beliefs, she would not have seen the picture of the dangerous spider as an apt portrait of the present spider..$^{19}$ Thus, even if there is no belief to identify the irrational fear of the spider and account for the intentionality of the emotion, there is a mental picture that is able to do a better job in both areas.

\footnotetext{
${ }^{19}$ Again, we have to remember that while some beliefs must act as external constraints, the particular beliefs, which act as the external constraints, are not required.
} 


\section{Conclusion}

Our discussion has shown that evaluative propositional states are not necessary for the identification and the intentionality of emotions. Sometimes imagination with its medium of mental pictures is better equipped to explain and identify a person's emotion. Since mental pictures are essentially intentional and representational, they can also provide the intentionality of emotions. If this is the case, then the cognitivist view is mistaken in claiming that emotions entail certain propositional attitudes, and, consequently, an analysis of emotions in terms of beliefs or judgments is unsatisfactory. ${ }^{201 * *}$

\section{References}

Adamos, M. M. (2001). Aristotle on emotions and contemporary psychology. In J. Hattiangadi, D. M. Johnson, and D. Sfendoni-Mentzou (eds.) Aristotle and Contemporary Science, II (226-235). New York: Peter Lang

- (2002). How are the cognitive and non-cognitive aspects of emotions related? Consciousness and Emotion, 3(2): 183-193

Alston, W. (1967). Emotion and feeling. In Paul Edwards' (ed.) The Encyclopedia of Philosophy. New York: Macmillan.

Arnold, M. (1960). Emotion and Personality. New York: Columbia University Press. Brentano, F. (1973). Psychology from an Empirical Standpoint. New York: Humanities Press.

\footnotetext{
${ }^{20}$ If my account regarding mental pictures is correct, then it also shows the inadequacy of the socalled weak cognitivist view according to which emotions may not require such strong epistemological states as beliefs, but they certainly require some type of propositional thought, and hence concepts. Although I am sympathetic to such accounts because they recognize the inadequacies of straightforward cognitivist theories, I disagree with their insistence on the use of propositions and concepts in emotions. As we have seen, sometimes concepts are not necessary for an emotional experience.

* I am indebted to Francis Daufer for his continuous support, constructive suggestions, and excellent insights. Without his help, this paper would not have been written. I am also grateful to Noel Fleming, Hubert Schwyzer, and Voula Tsouna for reading and commending on earlier drafts, and to all those who offered helpful criticism on a presentation of an earlier draft at the "Philosophy and the Emotions" conference of the Royal Institute of Philosophy, University of Manchester, July 2001. Also, I owe many thanks to my students and colleagues at Georgia Southern University for providing helpful suggestions, and to my Chair, Bruce Krajewski, for giving me a reduced teaching load in the fall of 2003. Finally, I would like to thank the editors, and especially Ralph Ellis and Tomasz Komendzinski for all their help.
} 
Dauer, F. W. (1993). Between belief and fantasy: A study of the imagination'. In Cohen, Guyer, and Putnam (ed.) Pursuit of Reason: Essays in Honor of Stanley Cavell. Austin:Texas Tech Press.

Deigh, J. (1994). Cognitivism in the theory of emotions. Ethics, 104: 824-854.

Goldie, P. (2000). The Emotions. Oxford: Oxford University Press.

Gordon, R. (1987). The Structure of Emotions. Cambridge: Cambridge University Press. Greenspan, P. (1988). Emotions and Reasons. London: Routledge.

Griffiths, P. (1997). What Emotions Really Are. Chicago: University of Chicago Press. Hume, D. (1962). A Treatise on Human Nature. New York: Macmillan Publishing Co. James, W. (1890). The Principles of Psychology. New York: Holt.

Joyce, J. (1961). Dubliners. New York: The Viking Press.

Kenny, A. (1963). Action, Emotion and Will. London: Routledge and Kegan Paul. Kraut, R. (1986). Feelings in Context. The Journal of Philosophy. 1:642-682.

Lazarus R. (1991). Emotion and Adaptation. New York: Springer.

Lyons, W. (1980). Emotion. Cambridge: Cambridge University Press.

Morreal, J. (1993). Fear without belief. The Journal of Philosophy, 90: 359-366.

Nash, R. A. (1989). Cognitive theories of emotion. Nous, 23: 481-504.

Nussbaum, M. G. (2001). Upheavals of Thought: The Intelligence of Emotions:Cambridge: Cambridge University Press.

- (1996). Aristotle on emotions and rational persuasion. In A. O. Rorty (ed.). Essays on Aristotle's Rhetoric. Berkeley: University of California Press.

- (1990). Love's Knowledge. Oxford: Oxford University Press.

Robinson, J. (1995). Startle. The Journal of Philosophy. XCIL53-74.

Solomon, R. (1993). The Passions. Indianapolis: Hackett Publishing Co.

Schachter, S. \& Singer, J. (1962). Cognitive, Social, and Physiological Determinants of

Emotional State. Psychological Review. 69:379-99.

de Sousa, R. (1987). Rationality of Emotion. Cambridge: MIT Press.

Stocker, M., (1987). Emotional thoughts. American Philosophical Quarterly. 24(1):59-69. Taylor, G. (1985). Pride, Shame and Guilt. Oxford: Oxford University Press. 